\title{
Ebeveyn Tutumlarının Ergenlerin Akademik Güdülenme Düzeyleri Üzerindeki Yordayıcı Etkisi
}

\section{Predictive Influence of Parental Attitudes on the Levels of Academic Motivation of the Adolescents}

\author{
Adem PEKER*, Nurseven KAĞIZMANLI**
}

\begin{abstract}
Öz: $\mathrm{Bu}$ araştırmanın amacı ergenlerin akademik güdülenme düzeyleri üzerinde ebeveyn tutumlarının yordayıcı etkisini incelemektir. Araştırma 2016-2017 eğitim öğretim yılında Erzurum ilinde beş farklı okul türünde öğrenim gören 358 öğrenci üzerinde gerçekleştirilmiştir. Çalışma grubunun \%59.8’i (214) erkek ve \%40.2'sinin (144) ise kız öğrencilerden oluşmaktadır. Çalışmaya katılan öğrencilerin yaş aralığı 14-19 arasındadır. Araştırmada ebeveyn tutumlarının öğrencilerin akademik güdülenme düzeyleri üzerindeki algılarını saptamak için Anne-Baba Tutum Ölçeği ile Akademik Güdülenme Ölçeği kullanılmıştır. Pearson korelasyon katsayısı ve çoklu regresyon analiz yöntemi kullanılarak verilerin işlem süreci yapılmıştır. Araştırma sonucunda ebeveyn tutumları ile akademik güdülenme ölçeklerinin alt boyutları arasında anlamlı ilişkilerin olduğu bulunmuştur. Araştırmada kendini aşma ve bilgiyi kullanma akademik güdülenme alt boyutlarının yordayıcısının anne-baba tutumunun kabul/ilgi alt boyutu olduğu belirlenmiştir. Keșif akademik güdülenme alt boyutunu, anne-baba tutumu ölçeğinin kabul/ilgi ve denetleme alt boyutlarının anlamlı bir şekilde yordadığı ortaya çıkarılmıştır.

Anahtar Kelimeler: Ebeveyn tutumları, akademik güdülenme, ergenler
\end{abstract}

\begin{abstract}
This study examines the predictive effect of parental attitudes on the academic motivation levels of the target adolescents. The study was carried out on 358 students in five different schools in Erzurum in the academic year of 2016-2017. The study group consisted of 59.8\% (214) male and $40.2 \%$ (144) female students. The age range of students participating in the study is between 14-19. The Parent Attitude Scale and the Academic Motivation Scale were used to determine students' attitudes to their parents. Pearson's correlation coefficient and multiple regression analysis method were used to analyze the data. As a result of the research, it was found that there is a significant relationship between parent attitudes and subscales of academic motivation scale. Another result of the research is that the predictor of self-motivation and use of knowledge is the acceptance/attention sub-dimension of the parental attitude. The discovery revealed that the academic motivation sub-dimension significantly predicted the acceptance/interest and control subdimensions of the parental attitude scale.
\end{abstract}

Keywords: Parent attitudes, academic motivation, adolescents

\section{Giriş}

Alanyazında güdülenme/motivasyon ile ilgili bir çok tanım yapılmıştır. Petty'e (2011) göre güdülenme iç ve çevresel uyaranlar tarafindan getirilen ve herhangi bir davranış sürecinin yürütülmesinin bir ön şartı olarak görülen içsel bir itici güçtür. Pintrich (2003) güdülenmeyi insanları bir davranışı yapmaya iten, devam etmelerini sağlayan ve işlerini bitirmede insanlara yardım eden bir kuvvet olarak nitelendirmektedir. Schunk (2000) güdülenmeyi hedefe ulaşmaya yönelik davranış süreci olarak tanımlarken, Glynn, Aultman ve Owens (2005) ise güdülenmeyi davranışları yönlendiren içsel durumlar olarak belirtmektedir. Ayrıca güdülenme, etkiye veya etkilere sebep olan davranışa yönelik bir eğilimin uyandırılması olarak da ifade edilmektedir (Atkinson, Atkinson ve Hilgrad, 1995). Özetle; güdülenmenin hedefe yönelik harekete geçirici bir süreç olduğu düşünülebilir (Schunk, Meece ve Pintrich, 2014).

\footnotetext{
*Dr. Öğretim Üyesi, Atatürk Üniversitesi, Kazım Karabekir Eğitim Fakültesi, Erzurum-Türkiye, e-posta: adem.peker@atauni.edu.tr

**Yüksek Lisans Öğrencisi, Köprüköy Atatürk Yatılı Bölge Ortaokulu, Erzurum-Türkiye, e-posta: nurseven.kagizmanli@hotmail.com
} 
Her ne kadar davranışların temeli güdülenme kavramına dayanıyor olsa da bir davranışa güdülenme düzeyi kişiden kişiye değişebilmektedir. Bununla birlikte insanların davranışa güdülenme şekilleri de farklılıklar göstermektedir. Herhangi bir davranışa güdülenme; bireyin kendisinin pasif olduğu dişsal boyun eğmeden, bireyin aktif olduğu kişisel kararlara kadar değişebilmektedir. Bu nedenle bazı kuramcılar güdülenmenin içsel ve dışsal olmak üzere iki boyutu bulunduğunu ifade etmişlerdir (Deci ve Ryan, 2002). Bu boyutlara göre; kişiyi bir davranışı yapmaya iten güç dışarıdan geliyorsa (cezadan kaçınma, ödül kazanma isteği vb.) güdülenme şekli dışsal, davranışı yapmaya iten güç içten geliyorsa (işten zevk alma, işi ilginç bulma, işten doyum sağlama vb.) güdülenme şekli içsel olarak belirtilmektedir.

İnsan davranışlarını açıklamada temel olarak kabul edilen güdülenme şeklinin insan hayatını değişik biçimlerde ve boyutlarda etkilediği söylenebilir. Bugünün başarı üzerine gelişen ve büyüyen dünyasında güdülenmenin etkisi eğitimde de kendisini göstermiştir. Genel olarak güdülenme kavramı akademik başarının önemli yordayıcılarından biri olarak kabul edilmektedir (Akbaş ve Kan, 2007; Devetak ve Glazar, 2010; Eryılmaz, Yıldız ve Akın, 2011; Kadıŏlu ve Uzuntiryaki, 2008). Benzer şekilde Pintrich ve Zusho (2002), yaptıkları çalışmalarda akademik güdülenme seviyesi arttıkça akademik başarının da arttığını ortaya koymuşlardır.

Güdülenme kavramı, öğrenmede de önemli bir yapı olarak açılanmaktadır (Lepper, Corpus ve Iyengar, 2005). Huang ve Waxman (1995) yaptıkları çalışmalarda farklı seviyelerde güdülenmiş öğrencilerin aynı zamanda farklı öğrenme seviyelerine sahip olduklarını göstermişlerdir. Kobala ve Glynn'e (2007) göre eğer bilgiler etkili bir şekilde öğretilmek isteniyorsa, öğrencilerin öğrenmeye güdülenmişlikleri arttırılmalıdır. Görüldüğg̈ gibi akademik güdülenme düzeyi arttıkça, paralel bir şekilde öğrenme düzeyi ve akademik başarı da artmaktadır (Stipek, 2002). Bu nedenle öğrenme ve başarı için eğitimde akademik güdülenme kavramı büyük bir önem teşkil etmektedir (Pintrich ve Schunk, 2002).

Akademik güdülenme, kişiye özgü akademik hedeflere ulaşmak için amaçlanan faaliyetleri başlatan ve sürdüren içsel bir süreç olarak belirtilmektedir (Pintrich ve Zusho, 2002). Akademik olarak güdülenmiş öğrenciler güdülenmemiş öğrencilere kıyasla yaptıkları işlerde zorluklar karşısında başarısızlığı kabullenip işlerini bırakmak yerine başarmak için daha çok denemektedirler. Ayrıca akademik olarak güdülenmiş öğrenciler boş zamanlarında bilgisayar tasarlamak, kitap okumak ve problem çözmek gibi faaliyetlerle meşgul olmaktadırlar (Görmez, 2014). Akademik motivasyonu yüksek öğrencilerin okulu ve öğrenmeyi değerli, öğrenmek gibi öğrenme eğiliminde olduklarını ve öğrenmeye dayalı etkinliklerden zevk aldıkları bulunmuştur (Eccles ve Wigfield, 2002; Zimmerman, 2008).

Bununla birlikte akademik güdülenme seviyeleri düşük öğrenciler ise yaptıkları işlerde az gayret gösterme, dikkatsizlik, derslerden kaçma gibi davranışlar sergilemekte, ayrıca bu güdülenme eksikliği belli bir süre sonra okulu bırakma ile sonuçlanabilmektedir (Ekstrom, Goertz, Pollack ve Rock, 1986). Nitekim, lise öğrencileri üzerinde okulu bırakma kararı ile ilgili yapılan bir araştırma sonucunda öğrencilerin okulu bırakma kararı almasında rol oynayan faktörlerden birinin de güdülenme eksikliği olabileceğini ortaya konmuştur (Bridgeland, Dilulio ve Morison, 2006; Rumberger, 1987; Tidwell, 1988). Araştırmalarda motivasyon eksikliğinin akademik başarısızlığın ana nedeni olduğu tespit edilmiştir (Scheel, Madabhushi ve Backhaus, 2009; Wigfield, Lutz ve Wagner, 2005).

Alanyazın incelendiğinde okul başarısının, öğrenme ve akademik güdülenmenin birbirleriyle yakından ilişkili kavramlar olduğu görülmektedir. Öğrencilerin okuldan istedikleri uyarıcıları aldıkları takdirde derslere olan ilgisinin artacağı, bu ilginin de okuldaki akademik başarıya ilişkin motivasyona katlı sağlayacağı ifade edilmektedir (Gray, 2017). Okulda elde edilen başarıların öğrencileri akademik olarak daha fazla motive ettiği vurgulanmaktadır (Areepattamannil, 2011; Ellmore ve Oyserman, 2012). Bu nedenle eğitimsel anlamda hedefler koymada ve öğrencilerin eğitimsel performansını yükseltmede akademik güdülenme kavramını ve güdülenme kavramının yordayıcılarını tespit etmek bir gereklilik olarak kabul edilebilir. Öğrencilerin akademik güdülenmişlik düzeylerini etkileyen birçok faktörden söz etmek mümkündür. Bu faktörlerden biri de aile olarak düşünülebilir. 
Aile, sosyal düzenin bir organizasyonudur. Kișiliğin temelleri aile içerisinde atılır. Çocuğun ilk öğrenmeleri aile içerisinde gerçekleşir ve belirli davranış kalıpları aile içerisinde kazanılır. Bununla birlikte ailenin çocuk ile iletişimi ve ilişki şekilleri çocuğun akademik başarı ve performansı üzerinde de etkilere sahiptir. Bempechat, Graham ve Jimenez (1999) yaptıkları araştırmalarda öğrenmeye yönelik teşvik etme, eğitimin değeri ve çabaların önemi hakkında çocuğu bilgilendirme, okul görevlerini tamamlamaları için çocuklarının zaman yönetimine yardım etme, çocuklarıyla hedefleri ile başarıları arasındaki ilişkileri tartışma gibi olumlu destek sağlayan ailelerin çocuklarının akademik olarak en iyi sonuçları aldıklarını göstermişlerdir. Bununla birlikte, ailenin çocuğa yönelik davranışları, çocuğun yetenekleriyle ilgili inanç ve beklentileri ve çocuğu kontrol şekillerinin çocukların başarı odaklı davranışları ile ilişkili olduğunu gösteren araştırmalar da bulunmaktadır.

Ebeveynlerin başarı ile ilgili inanç ve davranışları, çocukların kendi yeteneklerini ve öğrenme değerini nasıl algıladıklarına derin bir etkisi olabileceği ifade edilmektedir (Eccles, Roeser, Vida, Fredricks ve Wigfield, 2006). Eccles (2007), çocukların ebeveynlerin inançlarına yönelik öznel değerlendirmelerinin başarıya ilişkin alanlarda yeterlik algısı arasındaki ilişkiye aracılık etmede kritik bir rol oynadığını belirtmektedir. Böylece ebeveynler, çocukların motivasyon inançları üzerine sosyal-duygusal etkiler yaratmakta ve bu da çocukların eğitim performansını etkileyeceği düşünülmektedir. Beklenti-Değer Teorisinin öngörülerine uygun olarak, ebeveynlerin çocuklarının akademik becerilerini değerlendirmeleri ve bu yeteneklerin çocuk tarafından algılanışı arasındaki olumlu ilişki olduğu vurgulanmaktadır (Simpkins, Fredricks ve Eccles, 2015). Toplumsal bir bilişsel kuram olarak başarı hedefi teorisi, hem okul hem de aile bağlamlarının, öğrencilerin benimsediği hedef yönelimlere katkıda bulunduğunu iddia etmektedir (Maehr, 2001).

Akademik başarıya ek olarak çocuğun akademik güdülenmesinde de ailenin etkisinin olduğunu gösteren çalışmalar bulunmaktadır (Alfaro ve Taylor, 2015; Gottfried, A. E., Fleming, ve Gottfried, A.W., 1994; Kapıkıran ve Özgüngör, 2009; Kim, 2015). Gogoi (2014) aile içerisindeki önemli üyelerin çocuğu öğrenmeye teșvik etme derecesi, çocuğun öğreten kaynaklara ulaşmasını kolaylaştırma ve öğrenmeyi güçleştiren sebepleri ortadan kaldırma çocuğun akademik başarı alanındaki güdülenmesini etkilediğini belirtmiş̦ir. Gutman (2006), ailenin desteği ile öğrencinin akademik hedefe yönlenmesi arasında pozitif bir ilişkinin olduğunu belirlemiştir. Sonuç olarak; okul dışında aile ortamının, özellikle anne-babanın tutumlarının, çocukların öğrenmesinde anahtar niteliği taşıyan akademik güdülenme düzeyi üzerinde olumlu-olumsuz etkiler meydana getirdiği söylenebilir.

\section{Araştırmanın amacı}

Akademik güdülenme, belirli akademik hedeflere ulaşmak için faaliyet gösteren ve sürdüren iç süreçler olarak belirtilebilir. Akademik güdülenme, okul başarısının temel bir belirleyicilerinden biri olarak kabul edilebilir. Günümüzde öğrencilerin okula ilgilerini etkileyecek birçok faktör bulunmaktadır. Bununla birlikte lise dönemindeki akademik başarının üniversite seçimini dolayısıyla meslek seçimine etki etmesi okul yaşantısında akademik güdülenmenin önemini ortaya koymaktadır. Öğrencilerin akademik düzeyde nasıl ve neye motive oldukları ile ilgili sorular uzun yıllar araştırmaların ön saflarında yer almıştır. Yurt içi ve yurt dışı araştırmalar akademik güdülenmenin; öğrencilerin okula yönelik ilgileri, tutum ve davranışları, öz-yeterlikleri, kişilik özellikleri, kariyer ve gelecek beklentileri vb. birçok konu ile yakından ilişkili olduğunu göstermektedir. Bununla birlikte, öğrencilerin okuldaki akademik başarısını artırma, okuldaki devamsızlı̆̆ önleme, okula olan ilgiyi artırma gibi konularda daha kapsamlı bir anlayış sağlamak için ek çalışmalara ihtiyaç duyulmaktadır.

Akademik güdülenmenin akademik çıktılar ve öğrenme üzerindeki olumlu etkileri birçok araştırmada ortaya koyulmuştur (Dinçer ve Doğanay, 2017; Karaman ve Watson, 2017; Rigby, Deci, Patrick ve Ryan, 1992). Bununla birlikte öğrenme ve akademik başarı üzerinde etkiye sahip olan bir diğer faktör anne baba tutumları olarak öngörülebilir. Çocukların ilk öğrenmelerini sağladıklarından ve devam ettirdiklerinden dolayı anne ve babalar çocukları için ilk öğretmen olarak kabul edilebilir. Çocukların okulda öğrendikleri bilgiler aile içerisinde pekiştirilerek 
çocuğun davranışlarına yansıtılabileceği gibi anne babaların çocuklarına karşı olumsuz davranışları ve çocuk yetiştirmedeki yanlış tavırları da çocukların okulda öğrendiği bilgileri köreltici bir misyon üstlenebilir. Bütün bunlar göz önünde bulundurulduğunda algılanan anne baba tutumlarının çocuklardaki akademik güdülenme düzeylerini de etkileyeceği düşünülmektedir.

Eğitim-öğretim faaliyetlerinin temel amacı kalıcı öğrenmeler sağlamak ve akademik başarıyı artırmak olarak düşünüldüğü zaman; öğrencilerin akademik güdülenme düzeylerinin yüksek olması akademik başarıyı da yükselteceğinden güdülenmeyi etkileyen değişkenlerin anlaşılması öğrenme-öğretme faaliyetleri açısından önem arz etmektedir. Bu sebepten bu araştırmanın temel amacı; öğrencilerin akademik çıktıları üzerinde önemli bir yere sahip ebeveyn tutumlarının lise öğrencilerinin akademik güdülenmelerini yordama düzeylerini belirlemektir. Bu amaç doğrultusunda aşağıdaki sorulara cevap aranmaktadır:

1. Ebeveyn tutumları kendini aşma akademik güdülenme alt boyutunu anlamlı bir düzeyde yordamakta midir?

2. Ebeveyn tutumları bilgiyi kullanma akademik güdülenme alt boyutunu anlamlı bir düzeyde yordamakta midir?

3. Ebeveyn tutumları keşif akademik güdülenme alt boyutunu anlamlı bir düzeyde yordamakta midir?

\section{Yöntem}

\section{Araştırma modeli}

Araştırmada ebeveyn tutumlarının lise öğrencilerinin akademik güdülenmelerini yordama düzeyleri nicel analiz yönteminin genel tarama türü olan kesit alma modeli ile gerçekleştirilmiştir. $\mathrm{Bu}$ modele göre seçilen örneklem üzerinden genelleme yapılmasının daha yüksek olduğu ifade edilmektedir (Karasar, 2012).

\section{Çalışma Grubu}

Araştırmanın evrenini Erzurum il merkezindeki Milli Eğitim Bakanlığına bağlı ortaöğretim okulları oluşturmaktadır. Sistematik örnekleme yöntemi kullanılarak çalışmaya dâhil olacak öğrenci sayısı belirlenmiştir. Bu yöntem uygulanırken üç aşamalı bir işlem uygulanmıştır. İlk olarak örneklem aralı̆̆ 1 belirlenmiştir. $\mathrm{Bu}$ değer evren büyüklüğünün istenen örneklem büyüklüğüne bölünmesi ile elde edilir $(10.000 / 370=27)$. Bu değerin 27 olduğu bulunmuştur. İkinci aşamada ise 1 ile 10 arasında tesadüfen bir sayı tespit edilmiştir. Bu sayıda 9'dur. Son aşamada ise 9 sayısına 27 eklenerek araştırmaya katılacak kişiler belirlenmiştir. Oluşturulacak örneklem öğrenim gören öğrencilerin sırasına göre $36,63,90,117,144$. vb. sayıları ile ilişkilendirilen kişileri içermektedir. Bu işlem sonucunda örneklem büyüklüğünün $\% 95$ güven aralığında 370 kişiye kadar yetecek öğrenci sayısına denk gelecek beş okulun olmasının yeterli olacağı görülmüştür. Bu beş okulda basit tesadüfi (yansız) örnekleme yöntemi kullanılarak belirlenmiştir.

Çalışma grubunun \%59.8'i (214) erkek ve \%40.2'sinin (144) ise kız öğrenciler olmak üzere toplam 358 kişiden meydana gelmektedir. Öğrencilerin yaklaşık \%30'u 9.sınıf, \%25’i 10.sınıf, \%37'si 11.sınıf ve \% 8'inin ise 12.sınıfta öğrenim görmektedir. Çalışmaya katılan öğrencilerin yaş aralığı 14-19 arasındadır. Araştırma da ölçekler uygulanırken çalışma grubuna alınan öğrencilerin gönüllü olmasına dikkat edilmiştir.

\section{Veri toplama araçları}

Anne-Baba Tutumu Ölçeği (ABTÖ): Araştırmada Lamborn ve diğerleri (1991) tarafindan geliştirilip, Yılmaz (2000) tarafından Türkçe'ye uyarlanmış olan Anne-Baba Tutum Ölçeği kullanılmıştır. Ölçeğin ilkokul, lise ve üniversite öğrencileri için geçerlik ve güvenirlik analiz yapılmıştır. Öz bildirime dayalı 26 maddelik ölçekte "Kabul/ilgi", "Psikolojik Özerklik" ve "Denetleme" olmak üzere üç alt boyut bulunmaktadır. Ölçekten alınabilecek en düşük puan 26 iken en yüksek puan ise 104'dür. Puanların yükselmesi öğrencilerin anne-babalarını kendilerine 
karş1 ilgi gösterme, demokratik davranma ve denetleyici olma tutumlarını göstermektedir. Alt boyutların güvenirliği sırasıyla $.82, .76, .88$ olarak belirlenmiştir. Bu araştırma kapsamında ölçeğin lise öğrencileri için oluşturulan soru maddeleri kullanılmıştır. Bu çalışma kapsamında ölçeğin alt boyutları iç tutarlık güvenirlik katsayısı $.76, .70$ ve .80 olarak saptanmıştır.

Akademik Güdülenme Ölçeği (AGÖ): Araştırmada öğrencilerin akademik güdülenmelerinde meydana gelen farklılıkları belirlemek üzere Bozanoğlu (2004) tarafindan geliştirilmiş olan Akademik Güdülenme Ölçeği kullanılmıştır. Her bir madde bireysel cevaplandırmaya dayalı 5 li likert tipli 20 maddeden oluşan ölçek için alınabilecek en düşük puan 20 iken alınabilecek en yüksek puan ise 100 olarak belirlenmiştir. Ölçek "Kendini Aşma", "Bilgiyi Kullanma" ve "Keşif" alt boyutlarından meydana gelmektedir. AGÖ'nün Cronbach Alfa iç tutarlılık katsayıları kendini aşma alt boyutu için .76, bilgiyi kullanma alt boyutu için .76, keşif alt boyutu için .72 ve ölçeğin tamamı için ise .88 olarak ortaya çıkarılmıştır. Bu araştırma kapsamında ölçeğin tümü için .87 , kendini aşma, bilgiyi kullanma, keşif alt boyutlar içinde sırasıyla .74, .73, .65 iç tutarlık güvenirlik katsayısı bulunmuştur.

\section{İşlem}

Araştırma yapılmadan önce ölçeklerin okullarda uygulanması için kurumların izni alınmıştır. Araştırmacılar tarafindan izin alınan okullara gidilerek ölçek uygulamaları sınıf ortamında yapılmıştır. Sınıf ortamında araştırmanın yapılma amacı hakkında öğrencilere bilgiler verilmiştir. Gönüllük esasına dayalı olarak istekli kişilere ölçekler dağıtılmıştır. Öğrencilerin veri toplama araçlarının ortalama 20-25 dakika içinde yanıtlandığ gözlenmiştir.

\section{Verilerin analizi}

Araştırma kapsamında ebeveyn tutumları ve akademik güdülenme değişkenleri arasındaki ilişkiler Pearson korelasyon analizi ile incelenmiştir. Ayrıca ebeveyn tutumlarının ergenlerin akademik güdülenme düzeyleri üzerindeki yordayıcı etkisi ise aşamalı çoklu regreson analizi kullanılmıştır. Analiz sürecinden önce değişkenlerin çarpıklık ve basıklık katsayıları saptanmıştır. Çarpıklık katsayılarının -.04 ile 1.28 arasında; basıklık katsayıları -.53 ile 1.08 arasında değiştiği gözlenmektedir. Tablo 1 de araştırmadaki değişkenlerin çarpıklık ve basıklık katsayıları gösterilmiştir.

Tablo 1

Anne-Baba Tutumları ile Akademik Güdülenme Ölçeklerinin Alt Boyutlarına İlişkin Çarpıklık ve Basıklık Katsayıları

\begin{tabular}{ccccc}
\hline Değişkenler & \multicolumn{2}{c}{ Kurtosis (Basıklık) } \\
\hline & İstatistik & Standart Hata & İstatistik & Standart Hata \\
Kendini Aşma & -.49 & .13 & .28 & .26 \\
Bilgiyi Kullanma & -.99 & .13 & 1.08 & .26 \\
Keşif & -.54 & .13 & .10 & .26 \\
Kabul/İlgi & -.59 & .13 & .09 & .26 \\
Psikolojik Özerklik & -.04 & .13 & -.53 & .26 \\
Denetleme & 1.28 & .13 & .94 & .26 \\
$\mathrm{~N}$ & & \multicolumn{3}{c}{358} \\
\hline
\end{tabular}

Tablo 1 incelendiğinde anne-baba tutumları ile akademik güdülenme ölçeklerinin alt boyutlarına ilişkin verilerin normallik varsayımını karşıladığı anlaşılmaktadır. 
Araştırma alt problemine ilişkin analizler yapılmadan önce verilerin Mahalanobis katsayıları incelenmiştir. Bu incelemeye bağlı olarak 6 kişinin verileri analize dahil edilmemiştir. Ayrıca 4 öğrenciye ait veride ölçekler eksik doldurulduğu için analize kapsmına alınmamıştır. Bu işlemler sonucunda alt problemlerle ilgili analizler 358 veri ile sürdürülmüşür. Araştırmada verilerin analizi SPSS 22 programı ile yapılmıştır.

\section{Bulgular}

Araştırmanın bu aşamasında çalışmadaki değişkenler arasındaki ilişkilere yönelik sonuçlar gösterilmiştir. Bu ilişkiler belirlendikten sonra ebeveyn tutumlarının akademik güdülenmenin alt boyutlarını ne derecede yordadığını belirlemeye yönelik regresyon sonuçları sunulmuştur. Ebeveyn tutumları ve akademik güdülenme arasındaki ilişkileri belirlemek amacıyla yapılan Pearson Korelasyon analizi ile betimsel sonuçlar Tablo 2'de verilmiştir.

Tablo 2.

Ebeveyn Tutumları ile Akademik Güdülenme Arasındaki İlişkilere Yönelik Pearson Korelasyon Analizi ve Betimsel Sonuçlar

\begin{tabular}{|c|c|c|c|c|c|c|c|}
\hline & Değişkenler & 1 & 2 & 3 & 4 & 5 & 6 \\
\hline 1 & $\begin{array}{l}\text { Kendini } \\
\text { Aşma }\end{array}$ & & & & & & \\
\hline 2 & $\begin{array}{l}\text { Bilgiyi } \\
\text { Kullanma }\end{array}$ & $.71 *$ & 1 & & & & \\
\hline 3 & Keşif & $.63 *$ & $.65^{*}$ & 1 & & & \\
\hline 4 & Kabul/İlgi & $.14 *$ & $.11 *$ & $.14 *$ & 1 & & \\
\hline 5 & $\begin{array}{l}\text { Psikolojik } \\
\text { Özerklik }\end{array}$ & .02 & .06 & .06 & $-.11 *$ & 1 & \\
\hline 6 & $\begin{array}{l}\text { Denetleme } \\
\text { Aritmetik } \\
\text { Ortalama }\end{array}$ & $\begin{array}{l}-.02 \\
25.64\end{array}$ & $\begin{array}{c}.03 \\
24.10\end{array}$ & $\begin{array}{r}-.12 * \\
25.90\end{array}$ & $\begin{array}{l}.11 * \\
27.54\end{array}$ & $\begin{array}{c}.08 \\
19.10\end{array}$ & $\begin{array}{l}1 \\
11.11\end{array}$ \\
\hline & $\begin{array}{l}\text { Standart } \\
\text { Sapma }\end{array}$ & 4.95 & 3.99 & 4.64 & 4.54 & 3.68 & 3.75 \\
\hline & Çarpıklık & -.50 & -.99 & -.54 & -.59 & -.036 & 1.27 \\
\hline & Basıklık & .28 & 1.04 & .10 & .094 & -.54 & .95 \\
\hline
\end{tabular}

$\mathrm{N}=358, * \mathrm{p}<.05$

Tablo 2 incelendiğinde anne-baba tutum ölçeğinin kabul/ilgi alt boyutu ile akademik güdülenme ölçeğinin alt boyutları arasında düşük düzeyde, pozitif yönde anlamlı ilişkilerin olduğu gözlenmektedir. Anne-baba tutum ölçeğinin denetleme alt boyutu ile akademik güdülenme ölçeğinin keşif alt boyutu arasında ise düşük düzeyde, negatif yönde anlamlı ilişkilerin olduğu belirlenmiştir. Anne-baba tutum ölçeğinin denetleme alt boyutu ile kendini aşma ve bilgiyi kullanma; psikolojik özerklik ile de akademik güdülenme ölçeğinin tüm alt boyutları arasında anlamlı ilişkilerin olmadığı bulunmuştur. Dolayısıyla bu değişkenler çoklu regresyon analiz işlemine dâhil edilmemiştir.

Kabul/Illgi ebeveyn tutumunun akademik güdülenmenin kendini aşma alt boyutunu yordamasın ilişkin aşamalı çoklu regresyon analizi yapılmıştır. Sonuçlar Tablo 3'de gösterilmiştir.

Tablo 3.

Kabul/Ilgi Ebeveyn Tutumunun Akademik Güdülenmenin Kendini Aşma Alt Boyutunu Yordamasına İlişkin Aşamalı Çoklu Regresyon Analizi Sonuçları

\begin{tabular}{clccccccc}
\hline Model & $\begin{array}{l}\text { Yordayıc1 } \\
\text { Değişkenler }\end{array}$ & $\mathrm{B}$ & $\begin{array}{l}\text { Standart } \\
\text { Hata }\end{array}$ & $\beta$ & $\mathrm{t}$ & $\mathrm{R}^{2}$ & $\mathrm{~F}$ & $\mathrm{p}$ \\
\hline 1. & Sabit & 21.54 & 1.60 & & 13.46 & .018 & 6.71 & $.010^{*}$ \\
& Kabul/İlgi & .15 & .057 & .14 & 2.59 & & & \\
\hline
\end{tabular}

$* \mathrm{p}<.05 ; 1$.Model: $\mathrm{R}^{2}=.018, \mathrm{~F}_{(1-359)}=6.71$ 
Tablo 3 incelendiğinde akademik güdülenmenin kendini aşma alt boyutunu, anne-baba tutumu ölçeğinin kabul/ilgi alt boyutunun anlamlı bir şekilde yordadığı görülmektedir. Aşamalı çoklu regresyon analizi sonuçlarına göre kabul/ilgi boyutunun akademik güdülenmenin kendini aşma alt boyutunun yaklaşı \% 2'sini açıkladığı gözlenmektedir. Kabul/İlgi ebeveyn tutumunun akademik güdülenmenin bilgiyi kullanma alt boyutunu yordamasına ilişkin aşamalı çoklu regresyon analizi yapılmıştır. Sonuçlar Tablo 4'de gösterilmiştir.

Tablo 4.

Kabul/İlgi Ebeveyn Tutumunun Akademik Güdülenmenin Bilgiyi Kullanma Alt Boyutunu Yordamasına İlişkin Așamalı Çoklu Regresyon Analizi Sonuçları

\begin{tabular}{|c|c|c|c|c|c|c|c|c|}
\hline Model & $\begin{array}{l}\text { Yordayıcı } \\
\text { Değişkenler }\end{array}$ & B & $\begin{array}{l}\text { Standart } \\
\text { Hata }\end{array}$ & $\beta$ & $\mathrm{t}$ & $\mathrm{R}^{2}$ & $\mathrm{~F}$ & $\mathrm{p}$ \\
\hline \multirow[t]{2}{*}{1.} & Sabit & 21.51 & 1.29 & & 16.64 & \multirow[t]{2}{*}{.011} & \multirow[t]{2}{*}{4.13} & \multirow[t]{2}{*}{$.043 *$} \\
\hline & Kabul/İlgi & .094 & .046 & .11 & 2.032 & & & \\
\hline$*_{\mathrm{p}}<$ & & & & & & & & \\
\hline 1.M & $: \mathrm{R}^{2}=.011$, & $=4.1$ & & & & & & \\
\hline & ablo 4 incele & inde a & emik g & ne & kullan & alt $b$ & unu, : & e-baba \\
\hline tutumu & lçeğinin kabu & i alt bo & tunun anl & ir ş & yorda & gö & ktec & ş̧amalı \\
\hline çoklu & syon analiz & Iuçları & göre ka & boy & un aka & $\mathrm{k}_{\mathrm{g}}$ & enme & bilgiyi \\
\hline kullanr & alt boyutun & 1.1'ir & açıladıs̆ & lo & Kabu & je & ler & jeyn \\
\hline & & & & & & & & \\
\hline
\end{tabular}

Tablo 5.

Kabul/İlgi ve Denetleme Ebeveyn Tutumunun Akademik Güdülenmenin Keşif Alt Boyutunu Yordamasına İlișkin Așamalı Çoklu Regresyon Analizi Sonuçları

\begin{tabular}{|c|c|c|c|c|c|c|c|c|}
\hline Model & $\begin{array}{l}\text { Yordayıcı } \\
\text { Değişkenler }\end{array}$ & B & $\begin{array}{l}\text { Standart } \\
\text { Hata }\end{array}$ & $\beta$ & $\mathrm{t}$ & $\mathrm{R}^{2}$ & $\mathrm{~F}$ & $\mathrm{p}$ \\
\hline \multirow[t]{2}{*}{1.} & Sabit & 21.87 & 1.50 & & 14.59 & & & \\
\hline & Kabul/İlgi & .15 & .054 & .14 & 2.72 & .02 & 7.39 & $.007 *$ \\
\hline \multirow[t]{3}{*}{2.} & Sabit & 23.30 & 1.59 & & 14.66 & & & \\
\hline & Kabul/İlgi & .16 & .054 & .16 & 3.01 & .038 & 7.00 & $.003^{*}$ \\
\hline & Denetleme & -.18 & .065 & -.13 & -2.55 & & & \\
\hline
\end{tabular}

$* \mathrm{p}<.05$

1.Model: $\mathrm{R}^{2}=.020, \mathrm{~F}_{(1-359)}=7.39 ; 2$.Model: $\mathrm{R}^{2}=.038, \mathrm{~F}_{(2-358)}=6.99$

Tablo 5 incelendiğinde akademik güdülenmenin keşif alt boyutunu, anne-baba tutumu ölçeğinin kabul/ilgi ve denetleme alt boyutlarının anlamlı bir şekilde yordadığı görülmektedir. Aşamalı çoklu regresyon analizi sonuçlarına göre 1.aşama'da kabul/ilgi boyutunun akademik güdülenmenin keşif alt boyutunun \% 2'sini açıkladığı, 2. aşamada denetleme boyutunun akademik güdülenmenin keşif alt boyutuna \% 1.8'lik bir katkı sağladığ1 görülmüştür.

\section{Tartışma, Sonuç ve Öneriler}

$\mathrm{Bu}$ araştırmada lise öğrencilerinin ebeveyn tutumlarının akademik güdülenme düzeyleri üzerindeki yordayıcı etkisi incelenmiş̧tir. Elde edilen bulgular ışığında lise öğrencilerinin annebaba tutumu ölçeğinin kabul/ilgi alt boyutu ile akademik güdülenme ölçeğinin kendini aşma, bilgiyi, kullanma, keşif; denetleme alt boyu ile de keşif alt boyutu arasında anlamlı ilişkilerin olduğu görülmüştür. Araştırma sonuçlarına bakıldığı zaman ebeveyn tutumunun kabul/ilgi boyutunun akademik güdülenmenin kendini aşma ve bilgiyi kullanma alt boyutlanını pozitif yönde, düşük düzeyde açıkladığı saptanmıştır. Benzer bir biçimde akademik güdülenmenin keşif alt boyutunu, ebeveyn tutumunun kabul/ilgi boyutunu pozitif yönde, denetleme alt boyutunu ise 
negatif yönde, düşük düzeyde yordadığı belirlenmiştir. $\mathrm{Bu}$ çalışmanın sonuçları, ailenin öğrencinin öğrenme performanslarını etkilediğini öne süren daha önceki bulguları desteklemektedir (Álvarez, Suárez, Tuero, Núñez, Valle ve Regueiro, 2015; Valle, Regueiro, Rodríguez, Piñeiro, Freire, Ferradás ve Suárez, 2015). Buna ragmen yordama düzeyinin düşük olması başka yordayıc1 değişkenlerin de olacağı düşüncesini doğurmaktadır. Alanyazın incelendiğinde akademik güdülenmeyi kaygı (Bedel, 2013), psikolojik ihtiyaçlar (Güdül, 2015), sosyal destek (Kapıkıran ve Özgüngör, 2009), akademik öz-yeterlik (Cıla, 2015; Maltais, Duchesne, Ratelle ve Feng, 2017), içsel motivasyon (Trevino ve DeFreitas, 2014) gibi kavramların daha çok etkilediği belirtilmektedir.

Çalışmanın ilk bulgusunda ebeveynlerin kabul/ilgi tutumunun öğrencilerin akademik güdülenmelerinin kendini aşma boyutunu pozitif olarak ve düşük düzeyde açıkladığı gözlenmektedir. Alanda yapılan çalışmalar incelendiğinde ebeveynlerin çocuklarını kabul edici ve destekleyici davranışlarının akademik güdülenmelerini etkileyen faktörlerden biri olarak belirtildiği görülmektedir (Alfaro ve Taylor, 2015; Gottfried ve diğerleri 1994; Kapıkıran ve Özgüngör, 2009; Song, Bong, Lee ve Kim, 2015). Gogoi (2014) yaptığı araştırmada lise öğrencilerinin akademik güdülenme düzeyleri ile anne-babalarının davranış şekilleri; özellikle de kabul edici ve reddedici tutumları arasında anlamlı bir ilişki olduğu ve anne babaların çocuklarına yönelik kabul edici ve destekleyici davranışlarının onların akademik güdülenme düzeylerini olumlu yönde etkilediği sonucuna ulaşmıştır. Friedel, Cortina, Turner ve Midgley (2007) ebeveynlerin amaç yönelimlerinin ve destekleri ile öğrencilerin başarı yönelimli amaçları arasında pozitif bir ilişkinin olduğunu ifade etmiştir. Simpkins ve diğerleri (2015), ebeveyn desteğinin öğrencilerin akademik başarısı için önemli olduğunu belirtmiştir. Eccles (2007), ebeveynlerin çocuklarının yeteneklerine ilişkin algılamaları veya çocuğun başarısı için beklentileri gibi inançlarının, çocukların kendi yetenek algıları ve performansının belirleyicilerinden biri olarak kabul etmektedir.

Ebeveynlerden ilgi gören ergenlerin başarma güdüsünün arttığı, bunun sonucuna bağlı olarak, öğrenecekleri şeyleri keşfetmek ve kullanmak için yoğun bir istek duymalarına yol açabileceği söylenebilir. Böylece başarı duygusunu hisseden bireyler daha çok akademik çalışmaya yoğunlaşmaya motive olabilirler. Ebeveynlerin çocuklarını kabul düzeyleri öğrencilerin kendilerini akademik olarak iyi hissetme şansını artırabilecek bir faktör olarak düşünülebilir.

Çalışmanın diğer bir bulgusunda ebeveynlerin kabul/ilgi tutumunun öğrencilerin akademik güdülenmelerinin bilgiyi kullanma boyutunu pozitif olarak ve düşük düzeyde açıkladığ gözlenmektedir. Akademik güdülenmenin bilgiyi kullanma boyutu çocuğun öğrendiklerini hayatına ne boyutta yansıttığı ile ilişkili olarak değerlendirilmektedir. Bu çalışmanın sonuçları, ailenin çocuğuna karş1 göstermiş olduğu kabul/ilgi tutumunun öğrencinin akademik güdülenmesini artırdığını vurgulayana daha önceki bulguları desteklemektedir.

Aile-çocuk ilişkilerinde ebeveyn tutumları akademik güdülenmenin olumlu veya olumsuz yordayıcılarından bir olarak kabul edilmektedir (Grolnick ve Pomerantz, 2009). Ebeveyn kabul ve ilgisi, çocukların duygularına ve ifadelerine yanıt vermek, gelişimsel olarak uygun seçimi ve kendini ifade etmeye izin verme gibi davranışları içerebilir (Joussemet, Landry ve Koestner, 2008).

Ebeveynin çocuklarına karşı kabul edici davranışları onların farklı konularda çalışmasını, bilgiyi okul dışında kullanmasını, yeni bir şey öğrenmedeki istekliliğini artırabilir. Bilgiyi kullanırken ailesinde ilgi gören çocuk olumlu duygular daha fazla yaşayabilmektedir. $\mathrm{Bu}$ durumda çocuğun öğrenmeye karşı olan güdüsünün olumlu olmasına ve yeni bilgiler keşfetme davranışını göstermesine neden olabilir. Ayrıca ebeveynlerin bu tutumları öğrencideki içsel motivasyonun artmasına yol açabilir.

Ebeveynler, çocuklarının eğitim motivasyonlarında önemli bir rol oynamaktadır. Çocuklarına gerekli olanakları sağlama ve okulda iyi bir öğrenicinin performansına neden olan uygun eğitim ortamı oluşturmada katkıda bulunurlar. Ebeveynler, öğrencilerin eğitimle ilgili faaliyetlerini onaylamaları, takdir etmeleri, sıklıkla sözel destek vermeleri, okul çalışması için 
düzenli geribildirim vermeleri, okulda yapılan iş ve etkinlikler hakkında doğrudan konuşmaları öğrencilerin akademik olarak güdülenmesini artırabilir (Ali, 2016).

Ancak literatürde araştırma sonuçlarını desteklemeyen çalışmalar da bulunmaktadır. Cantley (2005) yaptığı araştırmada akademik güdülenme ile ailenin çocuğa yönelik ilgisi arasında pozitif bir sonuç elde edememiştir. Bu durumun araştırmaya katılan anne-babaların büyük bölümünün her ikisinin de çalışıyor olması, boşanmış olması ve bu gibi sebeplerden dolayı da çocuklarının akademik başarısı ve ödevleriyle yeterince ilgilenememeleri gibi sebeplerden kaynaklanabileceği vurgulanmıştır.

Araştırmanın diğer bir sonucunda akademik güdülenmenin keşif alt boyutunu, ebeveyn tutumunun kabul/ilgi ve denetleme alt boyutlarının anlamlı bir şekilde yordadığ 1 belirlenmiştir. Elde edilen bulgularda akademik güdülenmenin keşif alt boyutunu, ebeveyn kabul/ilgi tutumunun pozitif, denetleme boyutunun da negatif bir şekilde ve düşük bir düzeyde yordadığ görülmektedir. Ebeveynlerin kabul edici tutumları çocukların daha çok öğrenme faaliyetlerini sürdürme ve öğrenme etkinliklerini yapmasını sağlarken; denetleyici tavırları öğrenme istekliliğini olumsuz olarak etkilediği düşünülebilir. Velilerin çocukların akademik çalışmalarına doğrudan denetim etmesi, bir performans hedefi yöneliminden tatmin olmasını etkileyebilir. Bir çocuğun ödevini ve çalışmasını izleyen ebeveynler, çocukları ebeveynleri tarafindan yargılanmaktan daha fazla endişelendirebilir.

Alanyazın incelendiğinde ebeveyn denetlemesinin akademik güdülenme üzerindeki etkisi bu araştırma sonuçlarıyla farklılaştı̆̆ gözlenmektedir. Ebeveyn izlemesinin, akademik başarı, okul katılımı ve akademik motivasyonun artırılması ile ilişkilendirilmesi (Lowe ve Dotterer, 2013); annelerin ve babaların gözlemciliğinin Latin ergenlerin akademik motivasyonunun güçlü öngörücüsü olduğunu tespit edilmesi (Henry, Plunkett ve Sands, 2011) bu araştırma sonuçlarıyla benzerlik göstermemektedir. Yine başka bir çalışmada ebeveyn gözlemciliğinin gençlerin içsel motivasyonunu artırdığı ve okuldaki sorunları azalttığı rapor edilmektedir (Rodríguez, Piñeiro, Gómez-Taibo, Regueiro, Estévez ve Valle, 2017). Ergenlerin, ebeveynler ile daha sicak ve destekleyici ilişkiler bağlamında yüksek ebeveyn gözlem düzeyleri bildirdikleri zaman, öğrenme, okul yeteneklerine güven duyma ve okulda daha az davranışsal zorluk yaşama gösterme eğiliminde oldukları belirtilmektedir (Maltais ve diğerleri, 2017; Xia, Fosco ve Feinberg, 2016).

$\mathrm{Bu}$ farklılığının sebepleri arasında, çocuk yetiştirmedeki kültürel farklılıklar, lise öğreniminin üniversite eğitimi için bir basamak oluşturması gösterilebilir. Ebeveynin kabul/ilgisi çocuğun anlaşıldığını düşünmesini sağlayarak psikolojik bir rahatlık yaşamasına yol açabilir. Bu durumda öğrencinin derse olan ilgisini artırabilir. Denetleme yapıldığı zaman öğrencinin üzerinde bir baskı hissetmesine, bu baskının sonucunda akademik keşif ile ilgili olan konuya odaklanamama, o anı yaşayamama ve ders ile ilgili araştırma yapma isteğinin yerine getirememe gibi faaliyetlerin yapılmamasına neden olabilir. Özellikle üniversiteye giriş sınavı düşünüldüğünde ebeveynlerin lise öğrenimi sırasında çocuklarının iyi bir üniversite ya da meslek kazanmaları ile ilgili yaşadıkları kaygılar öğrencide ders ile ilgili dikkat dağınıklı̆̆ına, odaklanamama ve ders çalışmaya başlayamama gibi sorunların görülmesine yol açabilir. Öğrencinin gelecek ile ilgili endişeler yaşaması anlık odaklanmada güçlük yaşamasını sağlayabilir. Dolayısıyla bu bulguya göre çocuğun anne babasına ilişkin denetleyici algısı azaldıkça herhangi bir ödül beklentisi olmadan sadece merak ettiği ve ilgisini çektiği için öğrenme isteği artacă̆ 1 söylenebilir.

Anne-baba tutum ölçeğinin psikolojik özerklik alt boyutunun daha çok sosyal ilişkilerle ilişkili maddeleri içermesi ve denetleme boyutunun da okul dişında öğrencinin bilgiyi kullanması ve öğrendiklerini kullanmaktan ziyade daha çok çocuğun güvenliğine yönelik maddeleri kapsaması akademik güdülenmeyi açıklamamasının nedeni olarak düşünülebilir.

Sonuç olarak; öğrencilerin kapasitelerini tam olarak açığa çıkarabilmeleri ve eğitsel hedeflerine ulaşabilmeleri için akademik güdülenmelerinin artırılması önem arz etmektedir. Dolaylı olarak eğitimde istenilen sonuçların elde edilebilmesi ve eğitimin niteliğinin artırılması için de akademik güdülenme kavramı önemli bir nitelik taşımaktadır. Bu sebeplerden öğrencilerin akademik güdülenmelerini etkileyen faktörlerin anlaşılması gerekli olmaktadır. 
$\mathrm{Bu}$ çalışma öğrencilerin akademik güdülenmelerini etkileyen faktörlerden birinin de anne-baba tutumlarının olduğunu ortaya koymaktadır. Ebeveynlerin çocuklarının güdülenme düzeylerini olumlu yönde etkileyen tutumları benimsemeleri çocuklarından eğitim hayatlarında istenilen geri dönüşleri almalarını sağlayacaktır. Bu doğrultuda öğretmenlere ve uzmanlara anne babaların çocuklarının eğitimindeki etkileri hakkında bilgilendirici ve önleyici çalışmaların yapılması önerilebilir. Bununla birlikte ebeveynlere de kendi tutumlarının çocukları üzerindeki olumlu olumsuz etkilerine dair farkındalık temelli bireysel ve grup çalışmaları, ihtiyaç olması durumunda okul ortamında tüm aile üyelerinin katıldığı aile danışmalarının yapılması yararlı olabilir.

Bunların yanında sınırlılıkların belirlenerek araştırmanın tekrarlanması sonuçlar açısından daha genellenebilir bulguların elde edilmesini sağlayacaktır. $\mathrm{Bu}$ nedenle araştırmanın sınırlılıklarının göz önünde bulundurulması gerekmektedir. Araştırmanın sınırlılıkları arasında çalışma grubunun Erzurum ilinde devlet okullarındaki öğrenim gören sadece bir grup öğrenciyi içermesi, yaş aralığının 14-19 olarak sınırlandırılması, ebeveyn tutumlarının ayrı ayrı ele alınmaması, okul türü olarak çeşitliliğin az olması ve çalışma sonucuna ilişkin yordama düzeyinin düşük olması olarak sayılabilir. Ayrıca güdülenme ve anne-baba tutumu ile ilgili ölçeklerin alt boyutlarının bu kavramları tam olarak kapsamaması araştırmanın diğer bir sınırlılı̆̆ını oluşturmaktadır.

\section{Kaynaklar}

Akbaş, A. ve Kan, A. (2007). Affective factors that influence chemistry achievement (motivation and anxiety) and the power of these factors to predict chemistry achievement - II. Journal of Turkish Science Education, 4(1), 10-19.

Alfaro, E. C. ve Taylor, A. J. U. (2015). The longitudinal relation between academic support and Latino adolescents' academic motivation. Hispanic Journal of Behavioral Sciens, 37(3), 319-341.

Ali, A. S. (2016). The sources of motivation and academic motivation levels in Sakarya middle schools (Serdivan, Turkey). (Unpublished master dissertation). Sakarya University Institute of Educational Sciences, Sakarya.

Álvarez, A., Suárez, N., Tuero, E., Núñez, J. C., Valle, A. ve Regueiro, B. (2015). Implicación familiar, autoconcepto del adolescente rendimiento académico [Family involvement, adolescent self-concept and academic achievement]. European Journal of Investigation in Health, Psychology and Education, 3(5), 293-311. doi: 10.1989/ejihpe.v5i3.133

Areepattamannil, S. (2011). Academic self concept, academic motivation, academic engagement, and academic achievement: A mixed methods study of Indian adolescents in Canada and India. (Unpublished doctoral dissertation). Queen'a University, Ontario, Canada.

Atkinson L. R., Atkinson C. R. ve Hilgrad R. E. (1995). Psikolojiye giriş. K. Atalay, M. Atakay ve A. Yavuz (Çev:). İstanbul: Sosyal Yayınları.

Bedel, A. (2013). Sınıf tekrarı yapan ve yapmayan öğrencilerin akademik güdülenme ve kaygı düzeylerinin karşılaştırılması. Milli Eğitim Dergisi, 42(200), 111-121.

Bempechat, J., Graham, S. E. ve Jimenez, N. V. (1999). The socialization of achievement in poor and minority students: A comparative study. Journal of Cross-Cultural Psychology, 30, 139-158.

Bridgeland, J. M., DiIulio, J. J. ve Morison, K. B. (2006). The silent epidemic: Perspectives of high school dropouts. Washington, DC: Civic Enterprises, LLC.

Bozanoğlu, İ. (2004). Akademik güdülenme ölçeği: Geliştirilmesi, geçerliliğí, güvenilirliği. Ankara Üniversitesi Eğitim Bilimleri Fakültesi Dergisi, 37(2), 83-98.

Cantley, C. (2005). Predicting academic intrinsic motivation: The role of parents, teachers, and child factors. (Unpublished doctoral dissertation). St. John's University, New York.

Cıla, M. S. (2015). Anadolu lisesi 9. ve 10. sınıf ögrencilerinin akademik başarılarının akademik özyeterlik,mükemmeliyetçilik ve akademik güdülenmeden yordanması (Yayımlanmamış yüksek lisans tezi). Gazi Üniversitesi, Eğitim Bilimleri Enstitüsü, Ankara. 
Deci, E. L. ve Ryan R. M. (2002). Overview of self-determination theory: An organismic dialectical perspective. E. L. Deci ve R. M. Ryan (Yay. haz.). Handbook of selfdetermination research içinde (s. 3-36). New York: University of Rochester Press.

Deci, E. L. ve Ryan, R. M. (1992). The initiation and regulation of intrinsically motivated learning and achievement. A. K. Boggiano ve T. S. Pittman (Yay. haz.), Achievement and motivation: A social-development perspective içinde (s. 9-36). New York: Cambridge University Press.

Devetak, I. ve Glazar, S. A. (2010). The influence of 16-year-old Students' gender, mental abilities, and motivation on their reading and drawing submicrore presentations achievements. International Journal of Science Education, 32(12), 1561-1593.

Dinçer, S. ve Doğanay, A. (2017). The effects of multiple-pedagogical agents on learners' academic success, motivation, and cognitive load. Computers \& Education, 111, 74-100.

Eccles, J., Roeser, R., Vida, M., Fredricks, J. A. ve Wigfield, A. (2006). Motivational and achievement pathways through middle childhood. L. Balter ve C. S. Tamis-Le Monda, (Yay. haz.). Child Psychology: A Handbook of Contemporary Issues 2nd ed., içinde (s. 325-355). New York: Psychology Press.

Eccles, J. S. (2007). Families, schools, and developing achievement related motivations and engagement. J. E. Grusec ve P. D. Hastings (Yay. haz.), Handbook of socialization içinde (s. 665-691). New York: Guilford Press

Eccles, J. S. ve Wigfield, A. (2002). Motivational beliefs, values, and goals. Annual Review of Psychology, 53, 109-132. doi:10.1146/annurev. psych.53.100901.135153

Ekstrom, R. B., Goertz, M. E., Pollck, J. M. ve Rock, D. A. (1986). Who drops out of high school and why? Findings from a national study. Teachers College Record, 87, 356-373.

Ellmore, K. E. ve Oyserman, D. (2012). If 'we' can succeed, 'I' can too: Identity-based motivation and gender in the classroom. Contemporary Educational Psychology, 37, 176185.

Eryılmaz, A., Yıldız, İ. ve Akın, S. (2011). Investigating of relationships between attitudes towards physics laboratories, motivation and amotivation for the class engagement. Eurasian Journal of Physics and Chemistry Education (Special Issue), 59-64.

Friedel, J., Cortina, K. S., Turner, J. C. ve Midgley, C. (2007). Achievement goals, efficacy beliefs and coping strategies in mathematics: The roles of perceived parent and teacher goal emphases. Contemporary Educational Psychology, 32, 434-458. doi: 10.1016/ j.cedpsych. 2006.10.009

Glynn, S. M., Aultman, L. P. ve Owens, A. M. (2005). Motivation to learn in general education programns. The Journal of General Education, 54(2), 150-170.

Gogoi, K. P. (2014). Factors affecting academic achievement, motivation in high school student. International Journal of Education \& Management, 4(2), 126-129.

Gottfried, A. E., Fleming, J. S. ve Gottfried, A. W. (1994). Role of parental motivational practices in children's academic intrinsic motivation and achievement. Journal of Educational Psychology, 86, 104-113.

Görmez, I. (2014). The effect of field trip oriented instruction on ninth grade students' achievement in animal diversity unit, continuing and academic motivation. (Unpublished doctoral dissertation). Middle East Technocal University, Ankara.

Gray, D. L (2017). Is psychological membership in the classroom a function of standing out while fitting in? Implications for achievement motivation and emotions. Journal of School Psychology, 61, 103-121.

Grolnick, W. S. ve Pomerantz, E. M. (2009). Issues and challenges in studying parental control: Toward a new conceptualization. Child Development Perspectives, 3, 165-170.

Gutman, L. M. (2006). How student and parent goal orientations and classroom goal structures infl uence the math achievement of African Americans during the high school transition. Contemporary Educational Psychology, 31(1), 44-63. 
Güdül, M. D. (2015). Üniversite öğrencilerinin akademik motivasyon profillerinin psikolojik ihtiyaç doyumu, akademik erteleme ve yaşam doyumu ile ilişkisi (Yayımlanmamış doktora tezi). Anadolu Üniversitesi, Eğitim Bilimleri Enstitüsü, Eskişehir.

Henry, C. S., Plunkett, S. W. ve Sands, T. (2011). Family structure, parental involvement, and academic motivation in Latino adolescents. Journal of Divorce and Remarriage, 52, 370 390. doi:10.1080/10502556.2011.592414.

Huang, S. L. ve Waxman, H. C. (1995). Motivation and learning environment differences between Asian American and white middle school students in mathematics. Journal of Research and Development in Education, 28, 208-219.

Joussemet, M., Landry, R. ve Koestner, R. (2008). A self-determination theory perspective on parenting. Canadian Psychology, 49, 194-200.

Kadıoğlu, C. ve Uzuntiryaki, E. (2008). Motivational factors contributing to Turkish high school students' achievement ain gases and chemical reactions. American Educational Research Association, 24-28.

Kapıkıran, Ş. ve Özgüngör, S. (2009). Ergenlerin sosyal destek düzeylerinin akademik başarı ve güdülenme düzeyi ile ilişkileri. Çocuk ve Gençlik Ruh Sağglığı Dergisi, 16(1), 21-30.

Karaman, M. A ve Watson, J. C. (2017). Examining associations among achievementmotivation, locus of control, academic stress, and life satisfaction: A comparison of U.S. and international undergraduate students. Personality and Individual Differences, 111, 106110.

Karasar, N. (2012). Bilimsel araştırma yöntemi. Ankara: Nobel Yayınevi.

Kim, J. (2015). American high school student from different etnic backgrounds: The role of parents and the classroom in achievement motivation. Social Psychology of Education, $18,411-430$.

Koballa, T. R. ve Glynn, S. M. (2007). Attitudinal and motivational constructs in science learning. S. Abell, ve N. Lederman (Yay. haz.) Handbook of research on science education içinde (s. 75-102). Mahwah, New Jersey: LEA Publishers.

Lepper, M. R., Corpus, J. H. ve Iyengar, S. S. (2005). Intrinsic and extrinsic motivational orientations in the classroom: Age differences and academic correlates. Journal of Educational Psychology, 97(2), 184-196.

Lowe, K. ve Dotterer, A. M. (2013). Parental monitoring, parental warmth, and minority youths' academic outcomes: Exploring the integrative model of parenting. Journal Youth Adolescence, 42, 1413-1425.

Maehr, M. L. (2001). Goal theory is not dead-Not yet, anyway: A reflection on the special issue. Educational Psychology Review, 13(2), 177-185.

Maltais, C., Duchesne, S., Ratelle , C. F. ve Feng, B. (2017). Learning climate, academic competence, and anxiety during the transition to middle school: Parental attachment as a protective factor. Revue Européenne de Psychologie Appliquée, 67, 103-112.

Petty, S.D. (2011). Spirituality as a predictor of academic motivation among college students. (Unpublished doctoral dissertation). Capella University, Harold Abel School of Social and Behavioral Science, U.S.A.

Pintrich, P. ve Zusho, A. (2002). The development of academic self-regulation: The role of cognitive and motivational factors. A. Wigfield ve J. S. Eccles (Yay. haz.). Development of achievement motivation içinde (s. 249-284). San Diego, Ca: Academic Press.

Pintrich, P. R. (2003). A motivational science perspective on the role of student motivation in learning and teaching contexts. Journal of Educational Psychology, 82(1), 33-40.

Pintrich, P. R. ve Schunk, D. H. (2002). Motivation in education: Theory, research, and applications (2th Ed). New Jersey: Prentice Hall.

Rigby, C. S., Deci, E. L., Patrick, B. C. ve Ryan, R. M. (1992). Beyond the intrinsic-extrinsic dichotomy: Self-determination in motivation and learning. Motivation and Emotion, 16, $165-185$. 
Rodríguez, S., Piñeiro, I., Gómez-Taibo, M., Regueiro, B., Estévez, I. ve Valle, A. (2017). An explanatory model of maths achievement: Perceived parental involvement and academic motivation. Psicothema, 29(2), 184-190. doi: 10.7334/psicothema2017.32

Rumberger, R. W. (1987). High school dropouts: A review of issues and evidence. Review of Educational Research, 57, 101-121.

Scheel, M., Madabhushi, S. ve Backhaus, A. (2009). The academic motivation of at-risk students in a counseling prevention program. Counseling Psychologist, 37(8), 1147-1178.

Schunk, D. H. (2000). Motivation for achievement: Past, present, and future. Issues in Education. Contributions from Educational Psychology, 6, 161-165.

Schunk, D. H., Meece, J. L. ve Pintrinch, P. R. (2014). Motivation in education: Theory, reserach and applications. United Kingdom: Pearson Education Limited.

Simpkins, S. D., Fredricks, J. A. ve Eccles, J. S. (2015). Families, schools, and developing achievement related motivations and achievement. J. E. Grusec ve P. H. Hasting (Yay. haz.). Handbook of socialization: Theory and research içinde (s. 614-636). New York: Guilford Press.

Song, J., Bong, M., Lee, K. ve Kim, S. (2015). Longitudinal investigation into the role of perceived support in adolescent' academic motivation and achievement. Journal of Educational Psychology, 107(3), 821-841.

Stipek, D. (2002). Motivation to learn. Boston, MA: Allyn and Bacon Press.

Tidwell, R. (1988). Dropouts speak out: Qualitative data on early school departures. Adolescence, 23, 939-954.

Trevino, N. N. ve DeFreitas, S. C. (2014). The relationship between intrinsic motivation and academic achievement for first generation Latino college students. Social Psychological Education, 17, 293-306. DOI 10.1007/s11218-013-9245-3.

Xia, M., Fosco, G. M. ve Feinberg, M. E. (2016). Examining reciprocal influences among family climate, school attachment, and academic self-regulation: Implications for success. Journal of Family Psychology, 30, 442-454.

Valle, A., Regueiro, B., Rodríguez, S., Piñeiro, I., Freire, C., Ferradás, M. ve Suárez, N. (2015). Motivational profi les as a combination of expectations of self-efficacy and academic goals in college students. European Journal of Education and Psychology, 8(1), 1-8. doi: 10.1016/j.ejeps.2015.10.001.

Wigfield, A., Lutz, L. S. ve Wagner, A. L. (2005). Early adolescents development across the middle school years: Implications for school counselors. Professional School Counseling, 9, 112-119.

Yılmaz, A. (2000). Ana baba tutum ölçeğinin güvenirlik ve geçerlik çalışması. Çocuk ve Gençlik Ruh Sa ̌̆lı̆̆ Dergisi, 7(3), 160-172.

Zimmerman, B. J. (2008). Investigating self-regulation and motivation: Historical background, methodological developments, and future prospects. American Educational Research Journal, 45, 166-183. doi:10.3102/0002831207312909.

\section{Extended Abstract}

\section{Introduction}

The concept of motivation has primary prescription in explaining the vast majority, even if it is not all of human behavior. Despite many definitions of motivation, In the most general sense; it is the power that drives people to do things, to keep them going, and to help people to finish their jobs (Pintrich, 2003). Schunk (2000) defines motivation as a behavioral process to achieve the goal. It is also expressed as a tendency towards behavior that causes motivation, influence or effects (Atkinson, Atkinson \& Hilgrad, 1995).

The concept of motivation is also explained as an important structure in learning (Lepper et al, 2005). According to Kobala and Glynn (2007), if information is to be taught effectively, students should be motivated to learn. Academic motivation is an intrinsic process that initiates 
and sustains activities aimed at achieving person-specific academic goals (Pintrich \& Zusho, 2002). Academic-motivated students are more likely to accept failures in the face of difficulties in the work they do compared to non-motivated learners and try to accomplish rather than quit their jobs (Görmez, 2014). However, students with low levels of academic motivation exhibit low effort, carelessness, escape from classes, and this lack of motivation can lead to leaving school after a certain period of time (Ekstrom, Goertz, Pollack \& Rock, 1986).

It is stated that if the students get the stimulants they want from the school, the interest in the lessons will increase and this interest will provide the motivation for the academic success in the school (Gray, 2017). It is emphasized that the achievements in school are motivated more academically by students. It is emphasized that the achievements in school are motivated more academically by students (Ellmore \& Oyserman, 2012).

For this reason, it can be considered as a necessity to determine the concept of academic motivation and the predictors of motivation in raising the educational performance of the students in the educational sense. There are many factors that influence the academic motivation of students. One of these factors can be considered as family. It can be thought that the communication and relationship with the family has influence on the academic achievement and performance of the child.

Paternal attitudes and family environment can have effects on learning and educational success in all periods of childhood. Eccles (2007) found democratic parental attitudes to be positively related to academic achievement. In addition to academic achievement, there are studies showing that the child's academic motivation is also the effect of the family (Alfaro \& Taylor, 2015; Gogoi, 2014; Kim, 2015).

\section{Purpose}

The main purpose of this research is to examine whether the parents' attitudes that have a significant influence on the students' academic outcomes determine the levels of high school students' academic motivation.

For this purpose, the answers to the following questions are sought:

1. Do parental attitudes predict a self-transcending academic motivation sub-dimension at a significant level?

2. Do parental attitudes use knowledge to predict academic motivation sub-dimension at a significant level?

3. Are attitudes of parents predicting discovery, academic motivation sub-dimension at a meaningful level?

\section{Method}

\section{Research model}

The level of parental attitudes of high school students in their research to determine their academic motivation was carried out by the cross-sectional model, which is the general screening method of quantitative analysis.

\section{Working group}

The universe of the research is composed of the secondary schools affiliated to the Ministry of National Education in Erzurum province center. The number of students to be included in the study was determined using the systematic sampling method. When this method is applied, a three-step process is applied. First, the sampling interval is determined. This value is obtained by dividing the size of the universe into the desired sample size $(10,000 / 370=27)$. This value is found to be 27. In the second stage, a number between 1 and 10 was found by chance. It's 9 in this issue. At the last stage, 27 people were added to the number 9 to determine who would participate in the survey. The sample to be formed is $36,63,90,117,144$..etc. As a result of this process, it would be sufficient to have five schools corresponding to the number of students whose sample size is up to 370 in the $95 \%$ confidence interval. These five schools were identified by simple 
random (unbiased) sampling method. Of the study group, 59.8\% (214) were male and $40.2 \%$ (144) were female students.

\section{Analysis}

The relationships between the variables of academic motivation and parental attitudes were examined by Pearson correlation analysis. In addition, if parental attitudes are a predictor of academic motivation levels of adolescents, a multilevel regression analysis is used.

\section{Results and Discussion}

Findings revealed that there was a significant relationship between academic motivation of high school students and perceived parental attitudes. Predictive dimensions for the concept of academic motivation are self-transcendence, the use of knowledge and discovery. When we look at the results of the research, the predicting subscale of self-transcendence and use of knowledge has come to the fore as the acceptance/interest dimension of parental attitude. It is seen that the discovery academic motivation sub-dimension significantly predicts the acceptance/interest and control sub-dimensions of the parental attitude scale.

This study has also shown that parental attitudes have a qualifying or attenuating effect on the academic motivation of the students. Adopting attitudes that affect parents' motivation levels of their children positively will enable their children to get the desired returns in their educational life. In this respect, it may be advisable for teachers and experts to inform and prevent the effects of the parents' children's education. 